\title{
Screening for Retinopathy of Prematurity in a Regional Neonatal Intensive Care Unit
}

\author{
K. P. STANNARD, ${ }^{\prime}$ A. S. MUSHIN,${ }^{2}$ H. R. GAMSU ${ }^{3}$ \\ London
}

\begin{abstract}
Summary
Retinopathy of prematurity (ROP) is attracting renewed interest from ophthalmologists and neonatologists because of the improved survival of very low birthweight premature infants, some of whom develop blinding disease. Ophthalmologists may find increasing pressure from paediatric colleagues to provide a screening service for babies at risk. The results of the last twenty-two months of a continuing programme at this hospital demonstrate the benefits of active screening, but indicate some of the potential problems for ophthalmologists who are likely to become involved in this work now and in the future.
\end{abstract}

Following exacting clinical research by Patz and by Kinsey ${ }^{2}$ and others, and laboratory experiments by Ashton ${ }^{3}$ in the mid 1950s, the general feeling was that retinopathy of prematurity (ROP) was an entirely preventable disease. The role of oxygen in its pathogenesis and the value of oxygen restriction as a preventative measure became firmly entrenched in contemporary thought, provoking statements such as: "Retrolental fibroplasia (sic) can be either completely or almost completely eliminated by administering oxygen only at times of clinical need and then for as brief periods as possible and at concentrations less than 40 per cent". ${ }^{4}$

The adoption of such restrictions was associated with a decrease in the occurrence of the disease ${ }^{5}$ reinforcing such claims, although it has been suggested that the dogma of oxygen restriction as a method of ROP prevention, inadvertently caused an increase in perinatal mortality rate, as demonstrated by Cross in 1973. ${ }^{6}$

Thirteen years ago it was suggested that
ROP was once again occurring more frequently $^{7}$ and, increasingly, ophthalmologists and neonatologists have come to realise that the problem is far from vanquished. By the time pathological retinal changes are evident to the neonatologist performing external examination of the eye and direct ophthalmoscopy, the disease is usually very advanced. This indicates that there is a need for examination by ophthalmologists experienced in the techniques of indirect ophthalmoscopy and scleral depression, who are more likely to be able to detect the disease at an early stage.

There are a number of potential benefits to be gained by screening for and detecting at the earliest stage the peripheral retinal changes of ROP With the recent upsurge in the occurrence of the disease comes the realisation that more needs to be learned about its epidemiology and natural history if we are to find an effective treatment. Early detection of ROP allows the physician to inform the parents of the presence of the disease, keep them updated on its progress, and can prepare them

From: The 'Department of Ophthalmology and ${ }^{3}$ Neonatology, King's College Hospital and ${ }^{2}$ Department of Ophthalmology, The London Hospital.

Correspondence to: Mr K. P. Stannard, FRCS, Royal Victoria Infirmary, Newcastle upon Tyne NE1 4LP. 
for the discussion of treatment modalities if it becomes necessary to consider such options.

Recently, a randomised trial of cryotherapy for severe neovascular ROP has demonstrated the improved outcome in eyes which are treated compared with eyes which receive no treatment. This adds to the pressure on ophthalmologists to provide screening services to detect the disease as soon as possible and to treat it when threshold changes are reached.

The best way of detecting ROP at the earliest possible stage is actively to screen all neonates 'at risk'. For the last twenty-two months, from March 1986 to December 1987 inclusive, all babies admitted to the Neonatal Intensive Care Unit at King's College Hospital who were thought to be at risk of developing ROP have been screened, and this paper presents our findings so far, with a discussion of some of the problems of conducting such a screening programme, and some recommendations about the timing of examinations.

\section{Patients and Method}

The Neonatal Intensive Care Unit (NICU) at King's College Hospital comprises 20 cots, of which seven are designated for intensive care, with a turnover of approximately four hundred babies annually. About one-quarter of these babies weighed less than 1500 grammes, and most referrals from outside the district are those of preterm babies who require ventilation and specialist treatment of life threatening perinatal problems. All preterm babies who receive postnatal oxygen treatment have their arterial oxygen tensions monitored-if possible continuously, using indwelling arterial transducers-otherwise by continuous recording of transcutaneous $\mathrm{pO}_{2}$ and intermittent blood gas analysis, or a combination of these three techniques. All preterm infants weighing less than 1500 grammes at birth who are exposed to high oxygen tensions on a ventilator are given systemic vitamin $E$ in a dose of $10 \mathrm{mg} / \mathrm{kg}$ body weight daily.

The neonatologist referred all babies thought to be at risk of ROP and who were considered fit enough to be examined. The criteria for screening were:

(1) Very low birth weight ( $<1500$ grams)
(2) Postnatal exposure to oxygen, especially in preterm babies $(<37$ weeks at birth)

(3) Severe intercurrent illness such as intraventricular haemorrhage, severe infections, etc.

Often babies were referred who satisfied all three of the above criteria.

All the babies were seen as soon as possible after referral. A regular weekly ward round was instituted to allow examination of all new referrals and follow-up examinations of those previously assessed.

The pupils were dilated with Gutt. Cyclopentolate $0.5 \% \quad 30$ and 60 minutes beforehand. This produced adequate mydriasis and Gutt. Phenylephrine $2.5 \%$ was not used. Examinations were performed by one of us (K.P.S.) using an indirect ophthalmoscope, 28 Diopter hand lens and scleral depressor. A lid speculum did not significantly improve the peripheral retinal view, which was found to be adequate if the lids were manually parted, and seemed to lead to less reflex blepharospasm and better tolerance of the scleral depressor. Whenever the globe was directly manipulated with the depressor, the conjunctival sac was anaesthetised with a drop of Gutt. Benoxinate $0.4 \%$.

If ophthalmoscopy revealed clear ocular media with a normal fully vascularised retina no further follow-up occurred. If the retinal view was indistinct or the retina incompletely vascularised, re-examinations were performed every two weeks, and if signs of ROP were seen, the child was examined weekly until resolution occurred, or treatment was thought necessary, after which follow-up was performed as often as the clinical situation dictated. All babies who developed signs of ROP are being followed-up in the clinic.

\section{Results}

In the 22 months from March 1986 to December 1987, 169 neonates were thought to be at risk of ROP and referred for screening.

During that period 28 babies ( 16.6 per cent) developed signs of ROP and 141 (83.4 per cent) had no abnormal retinal signs.

Tables I and II show a breakdown of those 
Table I Numbers of babies with and without ROP according to gestational age at birth. (Parentheses show percentages of babies in the relevant age group).

\begin{tabular}{|c|c|c|}
\hline \multirow{2}{*}{$\begin{array}{l}\text { Gestational age } \\
\text { at birth } \\
\text { (weeks) }\end{array}$} & \multicolumn{2}{|c|}{ Number of babies } \\
\hline & Without ROP & With ROP \\
\hline$>37$ & $11(100 \%)$ & $0(0 \%)$ \\
\hline $31-37$ & $56(94.9 \%)$ & $3(5.1 \%)$ \\
\hline $25-30$ & $71(78.9 \%)$ & $19(21.1 \%)$ \\
\hline$<25$ & $3(33.3 \%)$ & $6(66.7 \%)$ \\
\hline Total & $141(83.4 \%)$ & $28(16.6 \%) \quad 169$ \\
\hline
\end{tabular}

Table II Number of babies with and without ROP according to birthweight. (Parentheses show percentages of babies in the relevant weight group).

\begin{tabular}{lcc}
\hline \multirow{2}{*}{$\begin{array}{l}\text { Birth weight } \\
\text { (grammes) }\end{array}$} & \multicolumn{2}{c}{ Number of babies } \\
\cline { 2 - 3 } & Without ROP & With ROP \\
\hline$>1500$ & $45(97.8 \%)$ & $1(2.2 \%)$ \\
$1001-1500$ & $60(86.9 \%)$ & $9(13.1 \%)$ \\
$751-1000$ & $24(80 \%)$ & $6(20 \%)$ \\
$<750$ & $12(50 \%)$ & $12(50 \%)$ \\
Total & $141(83.4 \%)$ & $28(16.6 \%)$ \\
\hline
\end{tabular}

patients with and without ROP according to birthweight and gestational age at birth.

Of all the babies who developed ROP, the majority ( 18 babies, 64.3 per cent) developed only stage 1 disease (demarcation line only) as the worst sign. Seventeen had bilateral stage 1 disease, and one baby had a demarcation line in one eye, but no signs of ROP in the fellow eye.

All the eyes with stage 1 ROP spontaneously regressed and developed morphologically normal retinal vascularisation. Palmer ${ }^{8}$ recommends that eventual morphological appearance of the retina be used to indicate outcome, because the accurate assessment of vision is extremely difficult in these infants, and the vision of a premature baby can be subnormal for neurological reasons.

Three babies developed bilateral stage 2 disease (ridge) and all three spontaneously resolved, leaving a morphologically normal retina. Seven babies progressed to stage 3 disease (neovascular ridge with extra retinal new vessel proliferation).

Table III indicates the severity of the disease, whether cryotherapy was performed and the morphological outcome.

One baby (No. 5) had a birthweight of over one kilogram, the others were all well below this, and all the babies had a gestational age at birth of 28 weeks or less. Six babies were first examined at a postmenstrual age of 32 weeks or less, and ROP was first detected between 33 and 35 weeks postmenstrual age. Due to severe illness, patient two was unfit for examination until 35 weeks postmenstrual age by which time stage one ROP was already present, although it was a further three weeks before neovascular changes were seen. Patient six was not fit enough for follow-up retinal examination until 34 weeks postmenstrual age, at which time neovascular ROP was detected.

Patient two did not receive retinal cryotherapy because only one eye had signs of early stage 3 ROP, which we do not consider an indication for intervention, and patient four though developing an area of severe neovascular change in one eye, did not have cryotherapy as he was too ill safely to undergo treatment. Fortunately, both children developed normal retinal vascularisation.

The most disappointing outcome occurred in patient six, where illness delayed the diagnosis of ROP and despite prompt treatment, one eye developed traction retinal detachment and the fellow eye developed severe peripheral scarring, albeit with a flat posterior

Table III Worst stage of ROP related to gestational age and birthweight

\begin{tabular}{|c|c|c|c|c|c|c|c|c|c|}
\hline \multirow[b]{2}{*}{ Worst stage } & \multirow[b]{2}{*}{ No } & \multicolumn{4}{|c|}{ Gestational age (weeks) } & \multicolumn{4}{|c|}{ Birthweight (grams) } \\
\hline & & $<25$ & $25-30$ & $31-37$ & $>37$ & $<750$ & $751-1000$ & $1001-1500$ & $>1500$ \\
\hline Stage 1 & 18 & 4 & 11 & 3 & 0 & 5 & 5 & 7 & 1 \\
\hline Stage 2 & 3 & 0 & 2 & 1 & 0 & 1 & 1 & 1 & 0 \\
\hline Stage 3 & 7 & 3 & 4 & 0 & 0 & 5 & 1 & 1 & 0 \\
\hline Total & 28 & & & & & & & & \\
\hline
\end{tabular}


Table IV Detection, management and outcome in babies developing Stage 3 ROP

\begin{tabular}{|c|c|c|c|c|c|c|c|c|}
\hline \multirow[b]{2}{*}{ No } & \multirow[b]{2}{*}{$B W$} & \multirow[b]{2}{*}{$G A$} & \multicolumn{3}{|c|}{ Postmenstrual age (weeks) } & \multirow{2}{*}{$\begin{array}{l}\text { Extent of } \\
\text { neovascularisation } \\
\text { (o'clock hours) }\end{array}$} & \multirow[b]{2}{*}{ Cryotherapy } & \multirow[b]{2}{*}{ Outcome } \\
\hline & & & $\begin{array}{l}\text { When first } \\
\text { examined }\end{array}$ & $\begin{array}{l}\text { When ROP } \\
\text { detected }\end{array}$ & $\begin{array}{l}\text { When stage } \\
3 \text { developed }\end{array}$ & & & \\
\hline 1 & 660 & 24 & 31 & 33 & 34 & $\begin{array}{l}\text { RE } 2 \text { hours; } \\
\text { temporally } \\
\text { LE } 2 \text { hours; } \\
\text { temporally }\end{array}$ & $\begin{array}{l}\text { YES temporal } \\
180^{\circ} \\
\text { YES temporal } \\
180^{\circ}\end{array}$ & $\begin{array}{l}\text { Morphologically } \\
\text { normal pattern of } \\
\text { retinal } \\
\text { vascularisation in } \\
\text { both eyes. }\end{array}$ \\
\hline 2 & 608 & 28 & 35 & 35 & 38 & $\begin{array}{l}\text { RE stage } 2 \\
\text { LE } 1 \text { hour; } \\
\text { nasally early stage } 3\end{array}$ & $\begin{array}{l}\text { NO } \\
\text { NO }\end{array}$ & $\begin{array}{l}\text { Morphologically } \\
\text { normal pattern of } \\
\text { retinal } \\
\text { vascularisation in } \\
\text { both eyes. }\end{array}$ \\
\hline 3 & 560 & 24 & 28 & 34 & 35 & $\begin{array}{l}\text { RE } 4 \text { hours; } \\
\text { temporally } \\
\text { LE } 4 \text { hours; } \\
\text { temporally }\end{array}$ & $\begin{array}{l}\text { YES temporal } \\
180^{\circ} \\
\text { YES temporal } \\
180^{\circ}\end{array}$ & $\begin{array}{l}\text { Bilateral minimal } \\
\text { disc dragging. }\end{array}$ \\
\hline 4 & 476 & 26 & 32 & 35 & 36 & $\begin{array}{l}\text { RE } 2 \text { hours; } \\
\text { temporally } \\
\text { LE stage } 2\end{array}$ & $\left.\begin{array}{l}\text { NO } \\
\text { NO }\end{array}\right\}$ Too ill & $\begin{array}{l}\text { Morphologically } \\
\text { normal pattern of } \\
\text { retinal } \\
\text { vascularisation in } \\
\text { both eyes. }\end{array}$ \\
\hline 5 & 1392 & 28 & 32 & 35 & 36 & $\begin{array}{l}\text { RE } 2 \text { hours; nasally } \\
\text { LE } 2 \text { hours; nasally }\end{array}$ & $\begin{array}{l}\text { YES } 360^{\circ} \\
\text { YES } 360^{\circ}\end{array}$ & $\begin{array}{l}\text { Morphologically } \\
\text { normal pattern of } \\
\text { retinal } \\
\text { vascularisation in } \\
\text { both eyes }\end{array}$ \\
\hline 6 & 718 & 24 & 30 & 34 & 34 & $\begin{array}{l}\text { RE } 12 \text { hours } \\
\text { LE } 6 \text { hours; } \\
\text { temporally }\end{array}$ & $\begin{array}{l}\text { YES } 360^{\circ} \\
\text { YES temporal } \\
180^{\circ}\end{array}$ & $\begin{array}{l}\text { Total right retinal } \\
\text { detachment. } \\
\text { Severe scarring } \\
\text { of left retinal } \\
\text { periphery with } \\
\text { flat posterior } \\
\text { pole. }\end{array}$ \\
\hline 7 & 804 & 26 & 31 & 33 & 35 & $\begin{array}{l}\text { RE } 4 \text { hours; nasally } \\
\text { LE } 2 \text { hours; } \\
\text { temporally }\end{array}$ & $\begin{array}{l}\text { YES } 360^{\circ} \\
\text { YES temporal } \\
180^{\circ}\end{array}$ & $\begin{array}{l}\text { Morphologically } \\
\text { normal right } \\
\text { retinal } \\
\text { vascularisation. } \\
\text { Minimal left disc } \\
\text { dragging. }\end{array}$ \\
\hline
\end{tabular}

$\mathrm{BW}=$ Birthweight (grams); GA = Gestational age (weeks).

pole. This child also has severe neurological deficit due to the long-term complications of periventricular haemorrhage.

In all babies, except number six, ROP was diagnosed at stage 1 and definite progression to stage 3 was seen in four within one week of diagnosis indicating the need for close followup. The eighteen babies developing stage 1 ROP which did not progress had very similar distribution in terms of birthweight and gestational age at birth. The ophthalmoscopic examination of individual babies revealed no obvious signs to indicate in advance which child would remain stable with stage 1 disease and which would progress to neovascular stage 3 . This reinforces our impression that stage 1 disease requires regular and frequent follow-up examinations, until signs of regression are visible.

Those babies who received cryotherapy had treatment to the avascular zone with some overlap onto the neovascular ridge. There are generally three methods of applying cryotherapy, each with its proponents - either to the avascular zone alone, ${ }^{9}$ or to the ridge alone ${ }^{10}$ or to both simultaneously. ${ }^{11}$ It has been 
our practice to assess the eyes to make a subjective classification of mild, moderate or severe neovascularisation, and in the latter two cases to offer cryotherapy after discussion with and informed consent from the parents.

Recently, the Cryotherapy for Retinopathy of Prematurity Cooperative Group have shown that randomised treatment to eyes with five or more contiguous or eight cumulative o'clock hours of stage 3 ROP was associated with a significantly less frequent unfavourable outcome than in untreated eyes. ${ }^{12}$ Cryotherapy was applied to the avascular retina only under local or general anaesthesia. The extent of neovascularisation is far greater when it reaches their threshold for treatment than ours. In our series only one baby (No. 6) would be considered eligible for treatment according to their criteria, and that baby had the least favourable outcome of all. It would seem that further investigation is needed to determine accurately the lowest threshold for treatment below which cryotherapy has no significant benefits over non-treatment, or complications outweigh the benefits.

This multicentre trial is the first to prove the benefits of cryotherapy in advanced disease, and emphasises the need for ophthalmologists to screen for and detect ROP as soon as possible, to allow close observation and the option for cryotherapy if the disease reaches the threshold described in the trial.

\section{Discussion}

Active screening of the very low birthweight premature infant presents the ophthalmologist with a number of problems. Some of these are minor annoyances, but others present major difficulties which might delay the detection of ROP.

The first major problem is that of visualisation of the fundus. The anatomical configuration of the neonatal eye when the infant has a postmenstrual age of less than 32 weeks is such that developmental medial opacities preclude a detailed view of the peripheral retina. The principal opacity is provided by the tunica vasculosa lentis (TVL) which is first recognised in the eight to nine millimetre long embryo as a branching vascular network arising from the distal end of the hyaloid artery. These communicate with an encircling capsulo-pupillary arcade surrounding the equator of the developing lens and from these latter vessels project the loops of the anterior portion of the TVL. ${ }^{13}$

The anterior TVL begins to show signs of closure and regression in the seventh month of intra-uterine development, which corresponds closely to the clinically observed involution of these vessels at 30 to 32 weeks of postmenstrual age. The hyaloid artery is usually completely involuted by the eighth month of development. Because of this, attempts to examine infants of less than 30 weeks postmenstrual age often fail because there is no useful view of the peripheral retina. This situation is made worse by the relative lack of optical clarity of the developing peripheral vitreous at this age, and in the very preterm infant developmental corneal haziness is also seen, though this tends to clear before the TVL and does not appear to add significantly to the difficulties. It might be considered therefore, that these factors determine the earliest postmenstrual age at which ROP might be visualised and detected, and as babies survive with ever decreasing gestational ages at birth, the early detection of ROP is likely to become increasingly difficult. In his recent paper, however, Fielder ${ }^{14}$ observes that ROP tends to occur within a relatively narrow range of postmenstrual age, perhaps indicating that the developing retina must reach a certain stage of maturity before it can mount a ROP response.

Other medial opacities, such as subhyaloid and superficial intraretinal haemorrhages, occur in some neonates, particularly if the birth has been prolonged and difficult, perhaps due to a Valsalva-like raised venous pressure encouraging rupture of the fragile capillary vessels. Such problems in the preterm infant may also contribute to the examination difficulties.

The examination is facilitated by adequate mydriasis but the drugs administered to dilate the neonatal pupil may be absorbed systemically and give rise to unwanted and even dangerous side effects. Guttae Cyclopentolate 0.5 per cent is generally accepted as a safe mydriatic in babies, but Bauer et al. ${ }^{15}$ have reported two cases of atropine-like toxicity, with side effects such as vomiting, ileus 
and distension. Our impression is that adequate mydriasis results from two drops of Cyclopentolate 0.5 per cent administered 30 and 60 minutes beforehand. The standard preparation of Guttae Phenylephrine 10 per cent may certainly be associated with unwanted side effects such as tachycardia and hypertension, and to prevent the likelihood of this happening, a more dilute form (2.5 per cent Phenylephrine) is easily available if the pupillary response to parasympatholytics is inadequate.

Another major difficulty in assessing these patients derives from the fact that, in general, they are very labile and can develop lifethreatening complications rapidly and recurrently, which may render them unable to withstand the additional stress of ophthalmoscopy. In some babies this may considerably delay the timing of the first examination, or cause postponement of follow-up examinations, leading to a reduced chance of detecting early ROP.

Adverse responses may result from stimulation of the oculocardiac reflex, which can lead to intense bradycardia. Stimuli reported to have caused this include traction on extraocular and lid muscles, the placement of lid specula, pressure on the globe-especially when using a scleral depressor-and even the minor trauma of having drops instilled. Clark et al. ${ }^{16}$ found that 31 per cent of neonates suffered bradyarrhythmias with ectopic beats when such stimuli were applied. The heart rate returns to normal when the stimulus is removed, but waiting for the child to return to a stable clinical condition can significantly add to the duration of each examination.

To minimise scleral depression with its attendant side effects one can often obtain an adequate view of the nasal and temporal retinal peripheries by utilising the oculocephalic reflex, which seems well establishd even in very immature babies. The major drawback to this technique is that it may not put the eyes into exactly the right position to visualise an area of interest, and as the eyes slowly return to the midline the view is lost, necessitating repeated manoeuvres to build up a composite view. If the child is ventilated this manoeuvre may put the infant at greater risk of cardiorespiratory complications if the endo- tracheal tube becomes accidentally dislodged. It should only be attempted if a paediatrician is in attendance to replace the tube, though in practice, the oculocephalic reflex is very infrequently used if the child is intubated, more reliance being placed on scleral depression to manipulate eye position.

The problems of simultaneous manipulation of the patient, lens and scleral depressor are magnified by the presence of other equipment around the baby. Often the most premature infants require ventilation for prolonged periods, and the presence of an endotracheal tube may prevent correct positioning of the hand lens. In our series, 37 babies were first screened or followed up when on a ventilator, but in 19 the examination had to be abandoned due to inability to obtain a satisfactory view, coupled with adverse cardiac responses provoked by touching the tubes. We would now recommend deferring the examination until the child is extubated, unless it is older than 32 weeks postmenstrual age and is likely to be ventilated for many weeks, because ROP might occur undetected.

In those babies who do not require intubation and ventilation, many need supplemental oxygen therapy via a head box. The removal of this oxygen supply, even via a tube held a few inches away, may occasionally invite adverse changes, and although these problems may be easily overcome by the assistant holding the oxygen tube next to the baby's mouth and nose, the inevitable fogging of the hand lens by warm humidified oxygen does nothing to facilitate the view.

Minor problems of limited access to the infant-perhaps lying in an incubator where the tray fails to slide out properly, necessitating examination through the scratched, optically unsatisfactory perspex hood-are exacerbated by the general discomfort of neonatal intensive care units, which are, of necessity, hot and noisy. A major design fault of our own unit is the inability to darken the rocms and produce the conditions of cool, quiet darkness preferred by most who perform indirect ophthalmoscopy. The provision of a dark room in the NICU for ROP screening is one way around this problem, but needs the babies to be transported to and from the 
examination area and is, perhaps, less preferable to examining them properly 'in situ'

In a regional referral unit there may be problems of arranging continuity of the screening process. Often babies are admitted for a short period of time to receive specialist treatment of a life-threatening event, and afterwards are returned to the referring unit. This may disrupt the provision of screening examinations, and if babies are transferred away before the retina is known to have fully vascularised, and screening is not provided locally, then ROP may go undetected. It is our practice to advise follow-up screening examinations at the local unit if the state of the retina is uncertain. All babies are given follow-up appointments at our own unit where the retinae can be re-examined if there is any indication of a visual problem. All babies who develop ROP are followed up by us, though local follow-up is also arranged if the referring centre is far away.

The timing of screening examinations varies amongst different workers. Ideally, all ROP sufferers should be detected when the disease commences, so that appropriate follow up can occur. The number of examinations should be kept to a minimum, timed appropriately to detect the condition as early as possible, thus reducing unnecesary retinal examinations before the disease occurs.

Some regimes advocate examination within a specified period such as seven weeks from birth ${ }^{17}$ whilst in 1974 the American Academy of Paediatrics suggested examination at discharge from the nursery. These are likely to fail to detect the earliest stage of ROP and it is conceivable that babies could develop ROP, spontaneously regress and pass completely undetected. This would give the false impression of a low incidence of ROP.

Screening all babies on a weekly basis from birth is likely to result in a number of fruitless examinations, especially in the very immature infant before the ocular media have cleared sufficiently to allow a view of the periphery. More recently it has been suggested that the first examination should be timed to coincide with a postconceptual age of approximately 32 weeks, when the media have cleared. One possible pitfall here, however, derives from the fact that although obstetricians and paediatricians estimate the gestational age of a baby at birth with increasing accuracy they are not infallable. It is possible for them to underestimate a baby's gestational age and errors of up to four weeks are not impossible. This means, for example, that a baby estimated to be 28 weeks gestational age could be a 32-week, small-for-dates infant. If the first retinal examination is deferred for four weeks until the child is at an estimated 32 weeks postmenstrual age, one may find that that examination reveals a more mature 36 -week baby-perhaps with established ROP.

We would therefore advocate that the first examination should take place as soon as possible after birth to check whether the maturity of the eye matches the alleged postmenstrual age-and from that the timing of the second examination can be calculated to assess the baby at about 32 weeks. Thereafter, we would reassess the retinae every fortnight until fully vascularised, and if ROP is discovered, weekly or more often, depending on the clinical condition of the infant.

We would recommend active screening for ROP because it is the only way the condition can be diagnosed early, thus giving the opportunity for possible intervention. Even if it is felt that present evidence does not yet justify active treatment, the reappearance of ROP in extremely small babies determines that more should be established about its epidemiology and natural history so that the value of different therapies can be investigated. This is a valuable service which we should endeavour to provide for all our paediatric colleagues involved in the management of such preterm babies.

We are indebted to Mrs E Cobb and Miss J Moore for secretarial assistance.

\section{References}

${ }^{1}$ Patz A, Hoeck LE, de la Cruze E: Studies of the effect of high oxygen administration in retrolental fibroplasia I. Nursery observations. $A m \quad J$ Opthalmol 1952, 35: 1248-53

2 Kinsey VE: Retrolental fibroplasia. Cooperative study of retrolental fibroplasia and the use of oxygen. Arch Ophthalmol 1956, 56: 481-543

${ }^{3}$ Ashton N, Ward B, Serpell G: Effect of oxygen on developing retinal vessels with particular reference to the problem of retrolental fibroplasia. $\mathrm{Br} \mathrm{J}$ Ophthalmol 1954, 38: 397-432

${ }^{4}$ Guy LP, Lanman JT, Dancis J: The possibility of 
total elimination of retrolental fibroplasia by oxygen restriction. Paediatrics 1956, 17: 247-9

${ }^{5}$ McDonald AD: Neurological and ophthalmic disorders in children of very low birthweight. $\mathrm{Br} \mathrm{Med}$ J 1962, 1: 895-900

${ }^{6}$ Cross KW: The cost of preventing retrolental fibroplasia. Lancet 1973, 2: 954-6

${ }^{7}$ Mushin AS: Retinopathy of prematurity-A disease of increasing incidence? Trans Ophthalmol Soc UK 1974, 94: 251-7

${ }^{8}$ Palmer EA, Biglan AW, Hardy RJ: Retinal ablative therapy for active proliferative retinopathy of prematurity: History, current status and prospects. In Contemporary Issues in Fetal and Neonatal Medicine: Retinopathy of Prematurity. Eds: Silvermann and Flynn. Blackwell Scientific Publications 1985; Chapter 8, 222

${ }^{9}$ Ben-Sira I, Nissenkorn I, Grunwald E, Yassur Y: Treatment of acute retrolental fibroplasia by cryopexy. Br J Opthalmol 1980, 64: 758-62

${ }^{10}$ Hindle MW and Leyton J: Prevention of cicatricial retrolental fibroplasia by cryotherapy. Can J Ophthalmol 1978, 13: 277-88

${ }^{11}$ McPherson AR, Hittner HM, Kretzer FL: Treat- ment of acute retinopathy of prematurity with cryotherapy. In retinopathy of Prematurity: Current concepts and controversies. Published: B.C. Decker Inc. 1986, 167-8

${ }^{12}$ Multicentre Trial of Cryotherapy for Retinopathy of Prematurity: Preliminary Results. Cryotherapy for Retinopathy of Prematurity Cooperative Group. Paediatrics 1988, 81: 697-706

${ }^{13}$ Mann I: The development of the Human Eye. Published by British Medical Association 1928, reprinted 1949, 205-224

${ }^{14}$ Fielder AR, Ng YK, Levene MI: Retinopathy of Prematurity: age at onset. Arch Dis Childhood 1986, 61: 774-8

${ }^{15}$ Bauer CR, Trottier MCT, Stern L: Systemic cyclopentolate toxicity in the newborn infant. $J$ Paediatr 1973, 82: 501-5

${ }^{16}$ Clark WN, Hodges E., Noel LP, Roberts D, Coneys M: The oculocardiac reflex during ophthalmoscopy in premature infants. Am J Ophthalmol 1985, 99: 649-51

${ }^{17}$ Palmer EA: Optimal timing of examination for acute retrolental fibroplasia. Ophthalmology 1981, 88: 662-8 